\title{
A pencil rescues impaired performance on a visual discrimination task in patients with medial temporal lobe lesions
}

\author{
Ashley R. Knutson, ${ }^{1}$ Ramona O. Hopkins, ${ }^{2,3}$ and Larry R. Squire ${ }^{1,4,5,6,7}$ \\ ${ }^{1}$ Veterans Affairs San Diego Healthcare System, San Diego, California 92161, USA; ${ }^{2}$ Department of Psychology and Neuroscience \\ Center, Brigham Young University, Provo, Utah 84143, USA; ${ }^{3}$ Department of Medicine, Pulmonary and Critical Care Division, \\ Intermountain Medical Center, Murray, Utah 84143, USA; ${ }^{4}$ Department of Psychology, ${ }^{5}$ Department of Psychiatry, \\ ${ }^{6}$ Department of Neurosciences, University of California, San Diego, California 92093, USA
}

\begin{abstract}
We tested proposals that medial temporal lobe (MTL) structures support not just memory but certain kinds of visual perception as well. Patients with hippocampal lesions or larger MTL lesions attempted to identify the unique object among twin pairs of objects that had a high degree of feature overlap. Patients were markedly impaired under the more difficult task conditions. However, the deficit was fully rescued when patients used a pencil to draw lines between the twin pairs, thereby eliminating the need to hold material in memory as they worked at each display. The perceptual demands of the task were presumably the same with or without this memory aid. Accordingly, the results suggest that the deficit on this and similar tasks, which involve comparisons across stimuli, are better understood in terms of impaired memory rather than impaired perception.
\end{abstract}

[Supplemental material is available for this article.]

Studies of the medial temporal lobe (MTL) have suggested that lesions to the MTL impair long-term memory while sparing immediate and working memory as well as perceptual and intellectual functions (Baddeley and Warrington 1970; Milner 1972; Shrager et al. 2008; Squire and Wixted 2011). Recently, there have been proposals that the MTL nevertheless serves a role in circumstances when tasks impose little or no delay (Warren et al. 2011, 2012; Watson et al. 2013). One key idea is that the MTL is important for perception in addition to memory. By this view, the perirhinal cortex is needed for discriminating among stimuli with complex features that include overlapping elements (Murray and Bussey 1999; Bussey et al. 2003; Lee et al. 2005; Barense et al. 2007, 2012; Baxter 2012a; Erez et al. 2013). For example, patients with MTL lesions were impaired when they needed to shift attention back and forth between seven stimuli with highly similar features in order to identify the unique item (Barense et al. 2007). One important issue in such studies is that, even though the stimuli are presented simultaneously, the number and complexity of the stimuli might sometimes exceed what can be managed within working memory (Lee and Rudebeck 2010; Jeneson and Squire 2012). As a result, long-term memory would be needed to support performance. A recent study of visual discrimination ability with MTL patients provided support for this view (Knutson et al. 2012).

In the present study, we tested the object discrimination ability of patients with MTL lesions using stimuli with high degrees of feature overlap. In each display, five, seven, or nine stimuli were presented (two, three, or four twin pairs plus a unique object). Participants needed to appreciate the conjunction of multiple features in order to identify the unique object. In a first condition, patients were impaired at the higher difficulty levels when they

\section{${ }^{7}$ Corresponding author}

E-mail Isquire@ucsd.edu

Article is online at http://www.learnmem.org/cgi/doi/10.1101/Im.032490.113. inspected each display and tried to find the unique object. This finding replicated previous work with this task (Barense et al. 2007; Knutson et al. 2012). In a second condition using the same displays, participants were instructed to use a pencil to draw lines between each twin pair. We reasoned that in this condition the perceptual demands of the task should remain the same. However, using a pencil should eliminate the need to hold material in mind and reduce the burden on working memory. Accordingly, if the deficit found in the first condition reflects impaired perception, performance should remain impaired. If the deficit reflects impaired memory, performance should now be intact.

Seven memory-impaired patients participated (Table 1). Of these, six have damage thought to be limited to the hippocampus (CA fields, dentate gyrus, and subicular complex), and one has larger lesions of the medial temporal lobe (MTL). K.E. became amnesic in 2004 after an episode of ischemia associated with kidney failure and toxic shock syndrome. L.J. (the only female) became amnesic during a 6-mo period in 1988 with no known precipitating event. Her memory impairment has been stable since that time. D.A., R.S., and G.W. became amnesic in 2011, 1998, and 2001, respectively, after drug overdoses and associated respiratory failure. J.R.W. became amnesic in 1990 following an anoxic episode associated with cardiac arrest. Estimates of MTL damage were based on quantitative analysis of magnetic resonance (MR) images from 19 age-matched, healthy males for K.E., R.S., G.W., and J.R.W., eight younger healthy males for D.A., and 11 agematched, healthy females for patient L.J. (Gold and Squire

C) 2013 Knutson et al. This article is distributed exclusively by Cold Spring Harbor Laboratory Press for the first 12 months after the fullissue publication date (see http://learnmem.cshlp.org/site/misc/terms. xhtml). After 12 months, it is available under a Creative Commons License (Attribution-NonCommercial 3.0 Unported), as described at http://creativecommons.org/licenses/by-nc/3.0/. 
Table 1. Characteristics of memory-impaired patients

\begin{tabular}{|c|c|c|c|c|c|c|c|c|c|}
\hline \multirow[b]{2}{*}{ Patient } & \multirow[b]{2}{*}{ Gender } & \multirow{2}{*}{$\begin{array}{c}\text { Age } \\
\text { (years) }\end{array}$} & \multirow{2}{*}{$\begin{array}{l}\text { Education } \\
\text { (years) }\end{array}$} & \multirow{2}{*}{$\begin{array}{c}\text { WAIS-III } \\
\text { IQ }\end{array}$} & \multicolumn{5}{|c|}{ WMS-R } \\
\hline & & & & & Attention & Verbal & Visual & General & Delay \\
\hline D.A. & M & 30 & 12 & 95 & 104 & 90 & 91 & 90 & 56 \\
\hline K.E. & M & 71 & 13.5 & 108 & 114 & 64 & 84 & 72 & 55 \\
\hline L.J. & $\mathrm{F}$ & 75 & 12 & 101 & 105 & 83 & 60 & 69 & $<50$ \\
\hline R.S. & $\mathrm{M}$ & 56 & 12 & 99 & 99 & 85 & 81 & 82 & $<50$ \\
\hline G.W. & $\mathrm{M}$ & 53 & 12 & 108 & 105 & 67 & 86 & 70 & $<50$ \\
\hline J.R.W. & $M$ & 49 & 12 & 90 & 87 & 65 & 95 & 70 & $<50$ \\
\hline G.P. & $\mathrm{M}$ & 67 & 16 & 98 & 102 & 79 & 62 & 66 & 50 \\
\hline
\end{tabular}

WAIS-III is the Wechsler Adult Intelligence Scale-III and the WMS-R is the Wechsler Memory Scale-Revised The WMS-R does not provide numerical scores for individuals who score below 50. IQ scores for R.S. and J.R.W. are from the WAIS-Revised, and the IQ score for D.A. is from the WAIS-IV.

2005). D.A., K.E., L.J., R.S., G.W., and J.R.W. have an average bilateral reduction in hippocampal volume of $35,49,46,33,48$, and $44 \%$, respectively (all values $>2.9$ SDs from the control mean). On the basis of two patients (L.M. and W.H.) with similar bilateral volume loss in the hippocampus for whom detailed post-mortem neurohistological information was obtained (Rempel-Clower et al. 1996), the degree of volume loss in these six patients likely reflects nearly complete loss of hippocampal neurons. The volume of the parahippocampal gyrus (temporopolar, perirhinal, entorhinal, and parahippocampal cortices) is reduced by $-5 \%$, $11 \%,-5 \%, 10 \%, 12 \%$, and $-17 \%$, respectively (all values within 2 SDs of the control mean). The minus values indicate instances where the volume was larger for a patient than for controls. The volumes for parahippocampal gyrus differ a little from volumes reported previously for these patients (Knutson et al. 2012) and are based on newly published, more detailed guidelines for identifying the caudal border of the gyrus (Franko et al. 2012).

One patient (G.P.) has severe memory impairment resulting from viral encephalitis. G.P. has demonstrated virtually no new learning since the onset of his amnesia, and during repeated testing over many weeks he does not recognize that he has been tested before (Bayley et al. 2005). G.P. has a bilateral reduction in hippocampal volume of $96 \%$. The volume of the parahippocampal gyrus is reduced by $94 \%$. Eight coronal MR images from each patient, together with detailed descriptions of the lesions, can be found in Supplemental Material.

Eight healthy individuals (five male) served as controls for the memory-impaired patients. Controls averaged $58.4 \pm 6.1$ yr of age (range $=23-76)$ and had $14.1 \pm 0.5 \mathrm{yr}$ of education. All procedures were approved by the Institutional Review Board at the University of California San Diego. Participants gave written informed consent prior to participation and were compensated.

The test consisted of 64 unique displays of five, seven, or nine nonsense objects, termed Fribbles, as used in earlier studies of object perception (Williams and Simons 2000; Barense et al. 2007). The Fribbles were computer generated using Bryce 5 software (Corel Corporation) and were composed of a main body and two or four appendages. Each display contained two, three, or four twin pairs plus one unique object that did not have a twin. The unique object could appear in any location in the display (Fig. 1).

The difficulty of each display was manipulated by varying the number of objects in each display (five, seven, or nine), the number of appendages on each object (two or four), the number of body colors in each display (two different body colors or only one body color), and the differences among the appendages (relatively salient or more subtle). Combinations of these components were used to create easier displays (difficulty levels 1-4, eight trials/difficulty level) and more difficult displays (difficulty levels 5-8, eight trials/difficulty level) (for details, see Knutson et al. 2012). At all difficulty levels, each appendage of the unique object always appeared on at least one of the twin pairs in the display. Accordingly, more than one appendage always needed to be considered to distinguish the unique object from the twin pairs. One of the eight displays at difficulty level 6 was identical to the display illustrated in an earlier study (Fig. 2c in Barense et al. 2007).

In the first condition, participants were told that they would see pictures of objects on a computer screen and that one object in each display did not have a twin pair. The task was to identify the unique object. The displays were presented in blocks of eight trials, beginning with difficulty level 1 and progressing to difficulty level 6. Difficulty levels 7 and 8 were presented in a subsequent testing session (with the exception of one hippocampal patient and one control participant who received difficulty levels 1-8 during one session). A printed reminder of the instructions was in view throughout testing. Performance was self-paced, and participants identified their choice by pointing to the computer screen. Accuracy and response times were recorded. The patients with hippocampal lesions and the controls were tested once. Patient G.P. with large MTL lesions was tested on two occasions separated by 1 mo.

In a second condition (scheduled up to 3 mo later), difficulty levels 5-8 (32 trials) from the standard test were presented on

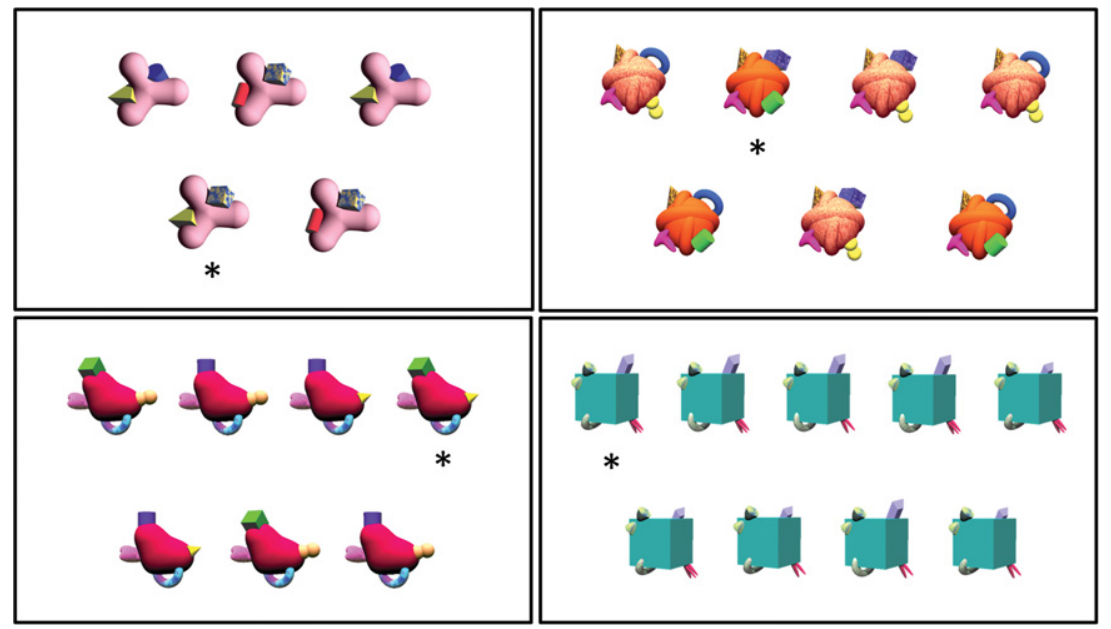

Figure 1. Sample displays. The task was to identify the unique object (asterisk). (Top row) Representative displays from difficulty levels 1 and 4. (Bottom row) Representative displays from difficulty levels 5 and 8 . At all difficulty levels, every appendage appeared on more than one object, and the unique object could not be identified by the presence of a single feature. Instead, the conjunction of multiple appendages defined the unique object. 

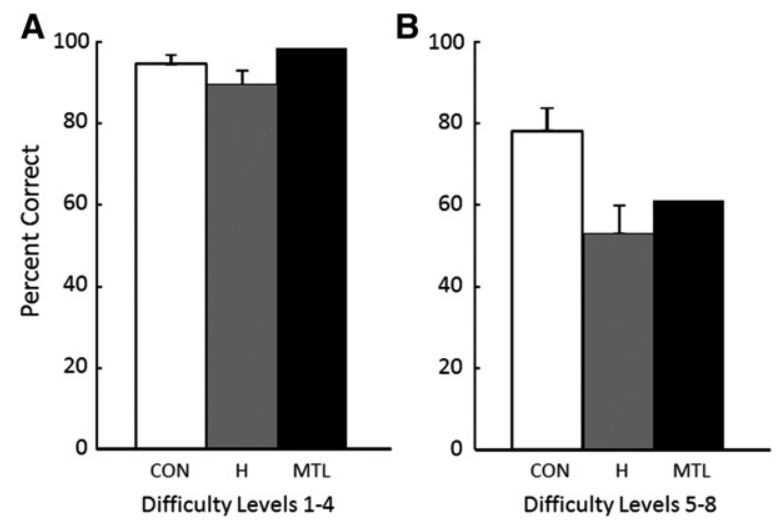

Figure 2. Accuracy at identifying the unique object for controls (CON, $n=8)$, patients with hippocampal lesions $(H, n=6)$, and a patient with large medial temporal lobe lesions (MTL, $n=1$ ) across eight levels of difficulty (eight trials/difficulty level). Patient performance was similar to that of controls at difficulty levels 1-4 $(A)$ but was impaired at difficulty levels 5-8 (B). Brackets show SEM.

individual sheets of paper, and participants were instructed to use a pencil to draw lines between each twin pair as each pair was identified. The intention of this condition was to eliminate the need to hold any material in mind as participants worked at each display. All the participants used the pencil, and afterward some commented that, with the aid of the pencil, there was no need to keep track of which twin pairs they had already identified. The instructions were in view throughout testing, and performance was self-paced. The data to be presented were based on accuracy and response times for all trials (correct and incorrect). The patients with hippocampal lesions and controls were tested once. Patient G.P. with large MTL lesions was tested on two occasions separated by 8 mo. Performance for five of the six patients in the hippocampal group was reported previously for difficulty levels 1-6 (first condition only). Performance of this group in the second condition (with the pencil) is presented here for the first time. In addition, performance for G.P. was reported previously for the first condition and for one of the two tests in the second condition (Knutson et al. 2012). In total, G.P. was tested on four occasions extending across $1 \mathrm{yr}$.

At difficulty levels 1-4 all participants performed well (Fig. $2 \mathrm{~A})$. Controls scored $94.3 \%$ correct, patients with hippocampal lesions scored $89.6 \%$ correct, and patient G.P. with large MTL lesions scored $98.4 \%$ correct. Response times were similar as well (controls $=12.9 \pm 1.7 \mathrm{sec}$, hippocampal patients $=11.5 \pm 0.6$ sec, patient G.P. $=13.2 \mathrm{sec})$. At difficulty levels $5-8$ the displays were more challenging (Fig. 2B). Controls scored 78.1\% correct, but patients with hippocampal lesions $(52.6 \%$ correct) were impaired $\left(t_{(12)}=3.0, P<0.05\right)$. G.P. $(60.9 \%$ correct) was impaired as well (one-sample $t$-test ${ }_{(7)}=3.2, P<0.05$ ). Response times were similar for controls and G.P. $(65.7 \pm 9.0 \mathrm{sec}$ and $70.3 \mathrm{sec})$, but patients with hippocampal lesions responded more quickly (37.1 $\pm 3.1 \mathrm{sec}, t_{(12)}=2.7, P<0.05$ relative to controls). The faster mean response times of the hippocampal patients appear to be due to response times at difficulty level 8 (55.8 $\pm 5.5 \mathrm{sec}$ vs. $142.5 \pm 22.2 \mathrm{sec}$ for controls). For levels $5-7$, the response times of hippocampal patients and controls were similar $\left(t_{(12)}=1.4\right.$, $P>0.20)$.

Figure 3 shows performance at difficulty levels $5-8$ when participants were given a memory aid to eliminate the need to hold material in mind as they worked at each display. In this condition, all participants performed well. Controls scored $86.3 \%$ correct, patients with hippocampal lesions scored $81.3 \%$ correct, and patient
G.P. with large MTL lesions scored $87.5 \%$ correct. The memory aid did not significantly improve control performance $(78.1 \%$ correct in Fig. 2 B vs. $86.3 \%$ correct in Fig. $3, P>0.10$ ), but substantially improved the performance of both the hippocampal patients (by $28.7 \%$, paired $t$-test, $t_{(5)}=9.7, P<0.01$ ) and G.P. (by $26.6 \%$ ). Response times were similar for controls, hippocampal patients, and patient G.P. $(57.8 \pm 6.6 \mathrm{sec}, 51.7 \pm 1.9 \mathrm{sec}$, and $63.0 \mathrm{sec}$, respectively).

To summarize, on tests of visual discrimination, patients performed well at the easier difficulty levels (1-4), but were impaired at difficulty levels 5-8. Three points deserve emphasis. First, patients were impaired only in the more difficult conditions (difficulty levels 5-8), even though at every difficulty level the task required discriminating among objects with overlapping features. This finding suggests that some other component of the task (besides the requirement to make perceptual discriminations) accounts for impaired performance. Second, the finding of an impairment in patients with circumscribed hippocampal lesions (not only patients with lesions that include the perirhinal cortex) suggests that the impairment is attributable to factors common to both brain areas, not to factors specific to perirhinal cortex. Inasmuch as the hippocampus has not been linked to object discrimination, the impairment after hippocampal lesions suggests that the impairment may be related to the importance of the hippocampus for long-term memory. Third, the impairment in patients was rescued by using a memory aid, a condition intended to reduce the burden on working memory. Specifically, there were 28 occasions when performance was tested with the memory aid (seven patients $\times$ difficulty levels $5-8$ ). Performance improved with the memory aid on 22 of these 28 occasions and remained the same on six occasions. Because the perceptual demands of the task were presumably the same with or without the memory aid, this finding provides particularly strong evidence that the deficit should be understood in terms of impaired memory rather than impaired perception.

Our results support earlier suggestions that memory likely plays a role in many of the tasks used to investigate the MTL's proposed role in visual perception (Hampton 2005; Suzuki 2009). Further studies of this issue will benefit from task designs that reduce the role of memory in task performance (e.g., Lee and Rudebeck 2010; Barense et al. 2012b). Last, in all studies of MTL function, there is the important issue of establishing the locus

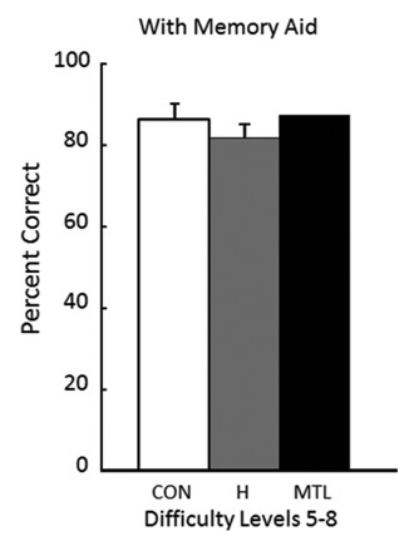

Figure 3. Accuracy scores for controls ( $\mathrm{CON}, n=8)$, patients with hippocampal lesions $(H, n=6)$, and a patient with large medial temporal lobe lesions (MTL, $n=1$ ) across difficulty levels $5-8$. In this condition, participants used a pencil to draw lines between the twin pairs, thereby eliminating the need to hold material in mind as they worked through each display. With this aid, patients performed as well as controls. Brackets show SEM. 
and extent of brain damage within patient groups and the possibility that direct or indirect damage lateral to the MTL might contribute to the deficits that are identified (Knutson et al. 2012; Insausti et al. 2013).

\section{Acknowledgments}

We thank Jennifer Frascino and Christine Smith for assistance, and Jill Leutgeb for helpful suggestions. This work was supported by the Medical Research Service of the Department of Veteran Affairs and National Institute of Mental Health Grant MH24600.

\section{References}

Baddeley AD, Warrington EK. 1970. Amnesia and the distinction between long- and short-term memory. J Verbal Learn Verbal Behav 9: $176-189$.

Barense MD, Gaffan D, Graham KS. 2007. The medial temporal lobe processes online representations of complex objects. Neuropsychologia 45: $2963-2974$

Barense MD, Groen IIA, Lee AC, Yeung L-K, Brady SM, Gregori M, Kapur N, Bussey TJ, Saksida LM, Henson RNA. 2012a. Intact memory for irrelevant information impairs perception in amnesia. Neuron 75: 157-167.

Barense MD, Ngo JK, Hung LH, Peterson MA. 2012b. Interactions of memory and perception in amnesia: The figure-ground perspective. Cereb Cortex 22: 2680-2691.

Baxter MG. 2012. It's all coming back to me now: Perception and memory in amnesia. Neuron 75: 8-10.

Bayley PJ, Frascino JC, Squire LR. 2005. Robust habit learning in the absence of awareness and independent of the medial temporal lobe. Nature 436: 550-553.

Bussey TJ, Saksida LM, Murray EA. 2003. Impairments in visual discrimination after perirhinal cortex lesions: Testing 'declarative' vs. 'perceptual mnemonic' views of perirhinal cortex function. Eur J Neurosci 17: 649-660.

Erez J, Lee AC, Barense MD. 2013. It does not look odd to me: Perceptual impairments and eye movements in amnesic patients with medial temporal lobe damage. Neuropsychologia 51: 168-180.

Franko E, Insausti AM, Artacho-Perula E, Insausti R, Chavoix C. 2012. Identification of the human medial temporal lobe regions on magnetic resonance images. Hum Brain Mapp doi: 10.1002/hbm.22170.

Gold JJ, Squire LR. 2005. Quantifying medial temporal lobe damage in memory-impaired patients. Hippocampus 15: 79-85.
Hampton RR. 2005. Monkey perirhinal cortex is critical for visual memory, but not for visual perception: Reexamination of the behavioural evidence from monkeys. Q J Exp Psychol B58: $283-299$.

Insausti R, Annese J, Amaral DG, Squire LR. 2013. Human amnesia and the medial temporal lobe: Neuropsychological and neurohistological findings for patient E.P. Proc Natl Acad Sci doi: 10.1073/ pnas.1306244110.

Jeneson A, Squire LR. 2012. Working memory, long-term memory, and medial temporal lobe function. Learn Mem 19: 15-25.

Knutson AR, Hopkins RO, Squire LR. 2012. Visual discrimination performance, memory, and medial temporal lobe function. Proc Natl Acad Sci 109: 13106-13111.

Lee AC, Rudebeck SR. 2010. Human medial temporal lobe damage can disrupt the perception of single objects. J Neurosci 30: 6588-6594.

Lee AC, Bussey TJ, Murray EA, Saksida LM, Epstein RA, Kapur N, Hodges JR, Graham KS. 2005. Perceptual deficits in amnesia: Challenging the medial temporal lobe 'mnemonic' view. Neuropsychologia 43: 1-11.

Milner B. 1972. Disorders of learning and memory after temporal lobe lesions in man. Clin Neurosurg 19: 421-446.

Murray EA, Bussey TJ. 1999. Perceptual-mnemonic functions of the perirhinal cortex. Trends Cogn Sci 3: 142-151.

Rempel-Clower NL, Zola SM, Squire LR, Amaral DG. 1996. Three cases of enduring memory impairment after bilateral damage limited to the hippocampal formation. J Neurosci 16: 5233-5255.

Shrager Y, Levy DA, Hopkins RO, Squire LR. 2008. Working memory and the organization of brain systems. J Neurosci $\mathbf{2 8}$ : $4818-4822$.

Squire LR, Wixted JT. 2011. The cognitive neuroscience of human memory since H.M. Annu Rev Neurosci 34: 259-288.

Suzuki WA. 2009. Perception and the medial temporal lobe: Evaluating the current evidence. Neuron 61: 657-666.

Warren DE, Duff MC, Jensen U, Tranel D, Cohen NJ. 2011. Observing degradation of visual representations over short intervals when MTL is damaged. J Cogn Neurosci 23: 3862-3873.

Warren DE, Duff MC, Jensen U, Tranel D, Cohen NJ. 2012. Hiding in plain view: Lesions of the medial temporal lobe impair online representation. Hippocampus 22: 1577-1588.

Watson PD, Voss JL, Warren DE, Tranel D, Cohen NJ. 2013. Spatial reconstruction by patients with hippocampal damage is dominated by relational memory errors. Hippocampus 23: 570-580.

Williams P, Simons DJ. 2000. Detecting changes in novel, complex three-dimensional objects. Vis Cogn 7: 297-322.

Received July 16, 2013; accepted in revised form August 6, 2013. 


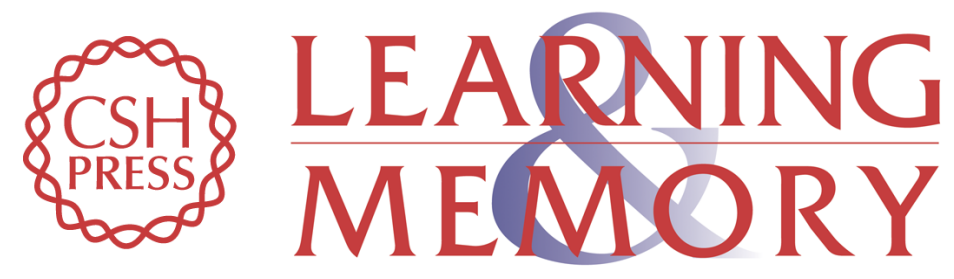

\section{A pencil rescues impaired performance on a visual discrimination task in patients with medial temporal lobe lesions}

Ashley R. Knutson, Ramona O. Hopkins and Larry R. Squire

Learn. Mem. 2013, 20:

Access the most recent version at doi:10.1101/Im.032490.113

\section{Supplemental http://learnmem.cshlp.org/content/suppl/2013/09/25/20.11.607.DC1 Material}

References This article cites 26 articles, 5 of which can be accessed free at: http://learnmem.cshlp.org/content/20/11/607.full.html\#ref-list-1

Creative This article is distributed exclusively by Cold Spring Harbor Laboratory Press for the Commons first 12 months after the full-issue publication date (see

License http://learnmem.cshlp.org/site/misc/terms.xhtml). After 12 months, it is available under a Creative Commons License (Attribution-NonCommercial 3.0 Unported), as described at http://creativecommons.org/licenses/by-nc/3.0/.

Email Alerting Receive free email alerts when new articles cite this article - sign up in the box at the Service top right corner of the article or click here. 